\title{
Transcatheter aortic valve-in-valve implantation: Go with the flow?
}

Oliver J. Liakopoulos, MD, and Thorsten Wahlers, MD

From the Department of Cardiothoracic Surgery, Heart Center, University of Cologne, Cologne, Germany. Disclosures: Authors have nothing to disclose with regard to commercial support.

Received for publication March 20, 2017; accepted for publication March 21, 2017; available ahead of print April 19, 2017.

Address for reprints: Oliver J. Liakopoulos, MD, Department of Cardiothoracic Surgery, Heart Center of the University of Cologne, Kerpener Strasse. 62, Cologne 50924, Germany (E-mail: oliver.liakopoulos@uk-koeln.de). J Thorac Cardiovasc Surg 2017;154:44-5

$0022-5223 / \$ 36.00$

Copyright (c) 2017 by The American Association for Thoracic Surgery

http://dx.doi.org/10.1016/j.jtcvs.2017.03.103

Transcatheter aortic valve-in-valve (ViV) implantation has emerged as an attractive alternative to reoperative surgical aortic valve replacement (AVR) for degenerated bioprosthetic aortic valves (BPV). ${ }^{1}$ The Valve-In-Valve International Data (VIVID) Registry, the largest multinational registry examining outcomes of $\mathrm{ViV}$ implantation, reported mortalities of $7.6 \%$ and $16.8 \%$ after 1 and 12 months, respectively. ${ }^{2}$ In a systematic review pooling data of 18 trials with 823 patients, transcatheter $\mathrm{ViV}$ insertion was associated with reduced incidences of both stroke $(1.9 \%$ vs $8.8 \%)$ and bleeding $(6.9 \%$ vs $9.1 \%$ ) relative to reoperative surgical AVR while providing similar valve hemodynamics and perioperative mortality $(7.9 \%$ vs $6.1 \%)$.

On the basis of the promising results of $\mathrm{ViV}$ implantation and of patients' preference for less-invasive procedures without permanent oral anticoagulation, the treatment strategy for patients requiring AVR is currently reshaping. The 2017 updated American Heart Association and American College of Cardiology guidelines for the management of patients with valvular heart disease have lowered the age limit for recipients of mechanical prostheses from 60 to 50 years and recommend an individually tailored choice of either a mechanical or bioprosthetic valve for patients between 50 and 70 years of age (class IIa, level B-NR). ${ }^{4}$ Consequently, it can be expected that the need for $\mathrm{ViV}$ implantation for structural deterioration of BPV is going to increase in the future and that patient selection will shift from patients judged by the heart team to be at high or prohibitive risk for reoperative surgical AVR to those considered to be at intermediate or low risk.

It is therefore time to improve our understanding of the underlying hemodynamic mechanisms after ViV insertion, which is currently based predominantly on feasibility trials and registries reporting clinical outcomes. ${ }^{1-3}$ The report by Hatoum and colleagues ${ }^{5}$ in this issue of the Journal elucidates some important aspects by quantifying in vitro changes of aortic sinus blood flow dynamics by

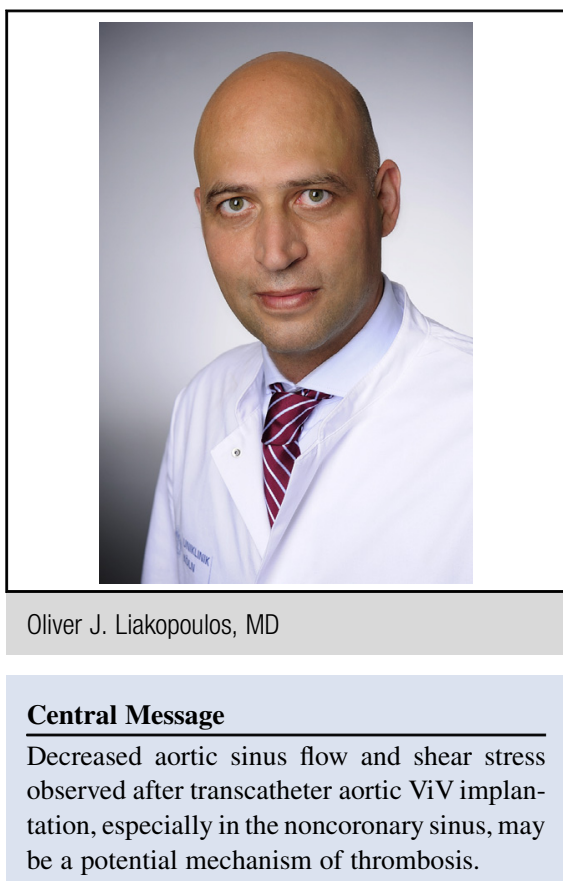

See Article page 32. high-resolution 2-dimensional particle image velocimetry before and after ViV insertion of 2 commercially available models (CoreValve $26 \mathrm{~mm}$ [Medtronic, Minneapolis, Minn] and Sapien $23 \mathrm{~mm}$ [Edwards Lifesciences Corp, Irvine, Calif]). ViV insertion was performed in an acrylic aortic valve chamber with a 23-mm Hancock bioprosthesis (Medtronic), and velocity fields within the coronary and noncoronary sinuses were captured. Two important results should be highlighted. First, both implanted ViV models reduced peak sinus flow velocity, vorticity, and shear stress, especially during systole, and may promote thrombus formation. Second, higher flow velocities and shear stress was measured in the coronary sinus than in the noncoronary sinus, making the coronary leaflets less susceptible to thrombus formation.

Translating these in vitro observations into direct clinical relevance seems premature. They do, however, certainly add another useful piece to the puzzle of leaflet thrombosis that has been reported recently after both transcatheter AVR and surgical AVR with bioprosthetic valves, ${ }^{6-8}$ a finding that could be even more frequent after $\mathrm{ViV}$ procedures and potentially could be counteracted by 
strict oral anticoagulation. Although this work does not consider other important mechanisms that may impact sinus flow and promote thrombus formation, such as differing designs (internally vs externally mounted BPV), size and calcification degree of the $\mathrm{BPV},{ }^{9}$ and finally appropriate sizing and positioning of the valve during ViV implantation, ${ }^{10}$ Hatoum and colleagues ${ }^{5}$ are to be congratulated for their fundamental work.

\section{References}

1. Bapat V, Attia R, Redwood S, Hancock J, Wilson K, Young C, et al. Use of transcatheter heart valves for a valve-in-valve implantation in patients with degenerated aortic bioprosthesis: technical considerations and results. J Thorac Cardiovasc Surg. 2012;144:1372-9; discussion 1379-80.

2. Dvir D, Webb JG, Bleiziffer S, Pasic M, Waksman R, Kodali S, et al. Valve-inValve International Data Registry Investigators. Transcatheter aortic valve implantation in failed bioprosthetic surgical valves. JAMA. 2014;312:162-70.

3. Phan K, Zhao DF, Wang N, Huo YR, Di Eusanio M, Yan TD. Transcatheter valve-in-valve implantation versus reoperative conventional aortic valve replacement: a systematic review. J Thorac Dis. 2016;8:E83-93. Erratum in: J Thorac Dis. 2016;8:E1111.
4. Nishimura RA, Otto CM, Bonow RO, Carabello BA, Erwin JP III, Fleisher LA, et al. 2017 AHA/ACC Focused Update of the 2014 AHA/ACC Guideline for the Management of Patients with Valvular Heart Disease: a Report of the American College of Cardiology/American Heart Association Task Force on Clinical Practice Guidelines. Circulation. March 15, 2017 [Epub ahead of print].

5. Hatoum H, Moore BL, Maureira P, Dollery J, Crestanello JA, Dasi LP. Aortic sinus flow stasis likely in valve-in-valve transcatheter aortic valve implantation. J Thorac Cardiovasc Surg. 2017;154:32-43.

6. Makkar RR, Fontana G, Jilaihawi H, Chakravarty T, Kofoed KF, de Backer O, et al. Possible subclinical leaflet thrombosis in bioprosthetic aortic valves N Engl J Med. 2015;373:2015-24.

7. Mack M, Holmes D. Bioprosthetic valve thrombosis: the harder one looks, the more one finds. J Thorac Cardiovasc Surg. 2016;152:952-3.

8. Mack MJ, Douglas PS, Holmes DR. Shedding more light on valve thrombosis after transcatheter aortic valve replacement. J Am Coll Cardiol. 2016;67: 656-8.

9. Stock S, Scharfschwerdt M, Meyer-Saraei R, Richardt D, Charitos EI, Sievers $\mathrm{HH}$, et al. In vitro coronary flow after transcatheter aortic valve-invalve implantation: a comparison of 2 valves. J Thorac Cardiovasc Surg. 2017;153:255-63.e1.

10. Azadani AN, Reardon M, Simonato M, Aldea G, Nickenig G, Kornowski R, et al. Effect of transcatheter aortic valve size and position on valve-in-valve hemodynamics: an in vitro study. J Thorac Cardiovasc Surg. 2017;153:1303-15.e1. 